\title{
Media Perceptions of Tommy John Surgery - Practice
}

\section{Demographics}

\section{What is your gender?}

Male

Female

\section{What is your age?}

\section{What is your ethnic origin? (Optional / Check one)}
American Indian
Asian
Black
White
$\bigcirc$ Hispanic
Other (please specify)

4. What is your primary media responsibility? Select the one that applies best.

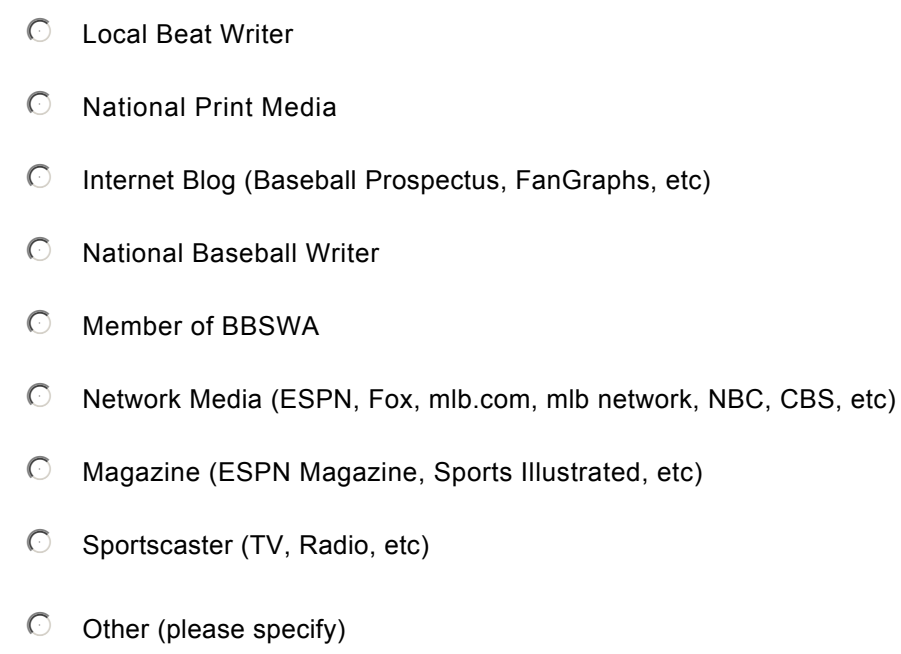

5. What percentage of your job is covering baseball? 


\section{Media Perceptions of Tommy John Surgery - Practice}

6. What geographical region do you cover? Select the one that best applies.

National

International

North

Northeast

Southeast

South

Southwest

$\bigcirc$ West

Northwest

Midwest

Other (please specify)

\section{Benefits from Tommy John Surgery}

1. How often are professional pitchers able to return to play professional baseball after Tommy John surgery?
$0 \%$
. $5 \%$
○ $10 \%$
○15\%
○20\%
○25\%
$30 \%$
○ $35 \%$
○ $40 \%$
○ $45 \%$
○0\% Never

2. Does Tommy John surgery improve PITCHING CONTROL compared to other pitchers without surgery?

Yes

No

I Don't Know

3. Does Tommy John surgery DECREASE PAIN with throwing?

$\bigcirc$ Yes

No

I Don't Know 


\section{Media Perceptions of Tommy John Surgery - Practice}

\section{Does Tommy John surgery IMPROVE PITCHING SPEED?}
Yes
No
I IDon't Know

\section{Does Tommy John surgery IMPROVE PITCHING PERFORMANCE?}
Yes
No
I Don't Know

\section{Indications for Tommy John Surgery}

1. In general, Tommy John surgery should be performed for: (check all that apply)
Shoulder Ligament
Elbow

$\square$ Shoulder

Decreased Throwing Velocity and Poor

2. Does an athlete need to have an elbow injury to have Tommy John surgery?
$\bigcirc$ Yes
$\bigcirc$ No
I Don't Know

\section{Recovery from Tommy John Surgery}

1. Estimate how long it would take to return to competitive throwing:
$\bigcirc<1$ month
(1-3 months
3 3-6 months
6 6-9 months
$\bigcirc 12$ months
13-15 months
16-18 months
○>18 months 


\section{Media Perceptions of Tommy John Surgery - Practice}

1. Estimate what is typically used by surgeons for Tommy John surgery?:

$\square$ Suture

$\square$ Tendon

$\square$ Plate

$\square$ Screws

Ligament

\section{Prior Experience (Select all that Apply)}

1. Do you know anyone who has had Tommy John surgery?

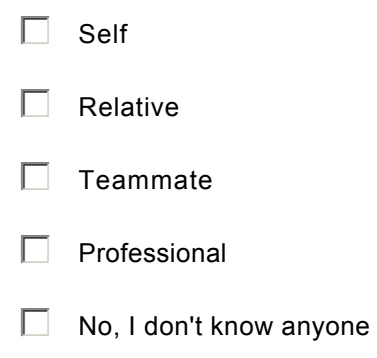

\section{Risks after Tommy John Surgery:}

1. Estimate the risk of FEELING numbness and tingling in the fingers after surgery:
$\bigcirc_{\text {Never }} 0 \%$
$\bigcirc 5$
$\bigcirc 10 \%$
15\%
○20\%
$\bigcirc 25 \%$
$30 \%$
○35\%
○ $40 \%$
$\bigcirc 45 \% \bigcirc 50 \%$

2. Estimate the risk of HAVING persistent elbow instability after surgery:
$\bigcirc 0 \%$
$\bigcirc 5 \%$
$\bigcirc 10 \%$
$\bigcirc 15 \%$
○20\%
$\bigcirc 25 \%$
$\bigcirc 30 \%$
$35 \%$
○ $40 \%$
○ $45 \%$
$\bigcirc 50 \%$

3. Estimate the risk of FEELING shoulder stiffness after surgery: $\bigcirc_{\text {Never }}{ }_{0 \%} \bigcirc{ }_{5 \%} \bigcirc{ }_{10 \%} \bigcirc{ }_{15 \%} \bigcirc{ }_{20 \%} \bigcirc{ }_{25 \%} \bigcirc{ }_{30 \%} \bigcirc{ }_{35 \%} \bigcirc 40 \% \bigcirc{ }_{45 \%} \bigcirc 50 \% \bigcirc$

4. Estimate the risk of NOT BEING ABLE TO RETURN TO PLAYING BASEBALL after surgery:

${ }_{0 \%} \bigcirc{ }_{5 \%} \bigcirc{ }_{10 \%} \bigcirc{ }_{15 \%} \bigcirc{ }_{20 \%} \bigcirc{ }_{25 \%} \bigcirc{ }_{30 \%} \bigcirc{ }_{35 \%} \bigcirc{ }_{40 \%} \bigcirc{ }_{45 \%} \bigcirc 50 \% \bigcirc$ Never

5. Estimate the risk of NOT BEING ABLE TO RETURN TO PITCH AT THE SAME LEVEL OF COMPETITION after surgery:

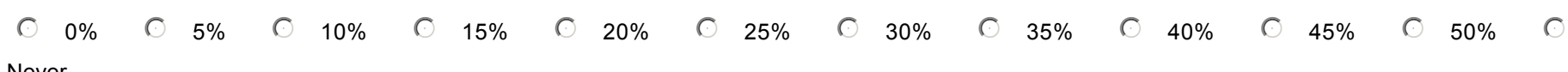
Never 


\section{Media Perceptions of Tommy John Surgery - Practice}

1. Are throwing injuries preventable?

Yes

No

I I Don't Know

2. Throwing injuries are related to: (select all that apply)

Number of Pitches

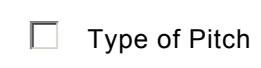

$\square$ Velocity

$\square$ Accuracy

3. Are pitch counts important for prevention of Tommy John surgery?
$\bigcirc$ Yes
$\bigcirc$ No
O I Don't Know

4. What is predictive of future injury in throwers? (select all that apply, then rank them 1, 2, 3 ,...in order of importance, with 1 being the most important)

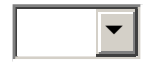
Number of Pitches
Throwing with Pain
Number of Innings
Previous Elbow Injury
Playing Pitch and Catch
Type of Pitch

\section{2nd Tommy John Surgery}

1. What is the success rate of someone having a 2nd Tommy John Surgery compared to the success rate of a 1st Tommy John surgery?

$\bigcirc$ Better

Same

$\bigcirc$ Worse

○I don't know 


\section{Media Perceptions of Tommy John Surgery - Practice}

2. Estimate how long it would take to return to competitive throwing after a 2 nd Tommy John Surgery:

$\bigcirc<1$ month

1-3 months

3-6 months

6 6-9 months

$\bigcirc 12$ months

13-15 months

(16-18 months

○>18 months 